\title{
Histologia e ultraestrutura do rim e rim cefálico do pacu ${ }^{1}$
}

\author{
Gerlane M. Costa ${ }^{2}$, Ana R. Lima ${ }^{3}$, Mendelson G. de Lima² e José R Kfoury Jr ${ }^{4}$
}

\begin{abstract}
Costa G.M., Lima A.R., Lima M.G. \& Kfoury Jr J.R. 2012. [Histology and ultrastructure of kidney and cephalic kidney in Pacu.] Histologia e ultraestrutura do rim e rim cefálico do pacu. Pesquisa Veterinária Brasileira 32(5):453-458. Universidade do Estado de Mato Grosso, Campus Alta Floresta, BR 208 Km 147, Alta Floresta, MT 78580-000, Bra-

zil. E-mail: gerlanemcosta@yahoo.com.br

The Pacu, Piaractus mesopotamicus, is a teleostei of the Characidae family, intensively cultivated in Brazil due to its rusticity, fast growth and easy adaptation. Morphological knowledge of the body systems including the lymphoid organs is necessary to improve fish production and supply subsidies for the maintenance of stocks. This study aimed to describe morphologically kidney and head kidney of Piaractus mesopotamicus, analyzing the cellular profile of each organ with the use of light microscopy and electronic transmission microscopy. The result of the macroscopic analysis showed that the localization of the kidney and head kidney is the same as found in the majority of the teleostei. The kidney presented a form in " $\mathrm{H}$ ", where the medium region is expanded on the natatorium bladder. The head kidney presented a dilatation in the cranial region of the kidney. In the transmission electronic microscopy we found ultrastructural similarities with other teleostei fish. It can be concluded that the lymphoid organs (kidney and head kidney) of Piaractus mesopotamicus are histologically and ultra-structurally similar to the other teleostei.
\end{abstract}

INDEX TERMS: Lymphoid organs, Piaractus mesopotamicus, kidney, cephalic kidney.

RESUMO.- O pacu, Piaractus mesopotamicus, é um teleósteo da Família Characidae, intensivamente cultivado no Brasil devido sua rusticidade, crescimento rápido e fácil adaptação. 0 conhecimento morfológico dos sistemas corpóreos, incluído órgãos linfóide, se faz necessário, para uma melhor produção no cultivo de peixes, fornecendo subsídios na manutenção dos estoques. 0 objetivo deste estudo foi descrever morfologicamente o rim e rim cefálico de Piaractus mesopotamicus, analisando os perfis celulares de cada órgão com o uso de microscopia de luz e microscopia eletrônica de transmissão. 0 resultado da análise macroscópica mostrou que a localização do rim e rim cefálico são as mesmas encontradas na maioria dos teleósteos. 0 rim apre-

\footnotetext{
${ }^{1}$ Recebido em 16 de julho de 2011.

Aceito para publicação em 10 de janeiro de 2012.

${ }^{2}$ Universidade do Estado do Mato Grosso (Unemat), Campus Alta Floresta, BR 208 Km 147, Alta Floresta, MT 78580-000, Brasil. *Autor para correspondência: gerlanemcosta@yahoo.com.br

${ }^{3}$ Instituto de Saúde e Produção Animal (ISPA), Faculdade de Medicina Veterinária, Universidade Federal Rural da Amazônia (UFRA), Av. Presidente Tancredo Neves 2501, Bairro Montese, Belém, PA 66077-530, Brasil.

${ }^{4}$ Faculdade de Medicina Veterinária e Zootecnia (FMVZ), Universidade de São Paulo (USP), Av. Prof. Dr. Orlando Marques de Paiva 87, Cidade Universitária, São Paulo, SP 05508-270, Brasil.
}

sentou uma forma em "H", onde a região média se expandia sobre a bexiga natatória. 0 rim cefálico se apresentou como uma dilatação na região cranial do rim, mostrando-se bem visível. Na microscopia eletrônica de transmissão também foram observadas similaridades ultraestruturais com outros teleósteos. Observando nossos resultados concluímos que histologicamente e ultraestruturalmente, os órgãos linfóides rim e rim cefálico de Piaractus mesopotamicus são similares aos de outros teleósteos.

TERMOS DE INDEXAÇÃO: Órgãos linfóides, Piaractus mesopotamicus, rim, rim cefálico.

\section{INTRODUÇÃO}

Piaractus mesopotamicus, comumente conhecido como pacu, é um teleósteo da família Characidae, sendo endêmico na bacia dos rios Paraná-Paraguai (Severi 2000). Peixe de escamas, com corpo rombóide e achatado lateralmente, possui coloração uniforme, variando do castanho ao cinza-escuro, com o ventre amarelado. Apresenta respiração branquial e sobrevive em ambientes naturais ou em viveiros de criação.

Segundo Agius \& Roberts (2003), nos teleósteos a hematopoiese ocorre principalmente no estroma do baço, no 
interstício dos rins e, em menor extensão, nas áreas peri-portais do fígado, submucosa do intestino e timo, uma vez que os peixes são desprovidos de medula óssea e de linfonodos (Tavares Dias \& Moraes 2004). Entretanto, há variações, podendo determinada espécie ter um ou mais órgãos com tecidos mielóides e linfóides associados. Os teleósteos apresentam quantidade variável de centros melanomacrófagos ou agregados de macrófagos nos diferentes tecidos, em particular fígado, baço e rim (Messeguer et al. 1994). Os centros melanomacrófagos são comumente nodulares com delicada cápsula argirofílica e geralmente restrito aos canais vasculares (Agius 1985).

Devido a uma lacuna de conhecimento a respeito da morfologia e função dos órgãos linfo-hematopoiéticos dos teleósteos, surge uma área que necessita de estudos aprofundados para que seja possível melhorar os métodos de criação até então disponíveis. Desta forma, o objetivo deste artigo foi realizar um estudo histomorfológico e análise dos componentes celulares dos órgãos linfóides rim e rim cefálico em Piaractus mesopotamicus, com o uso de microscopia de luz e eletrônica de transmissão.

\section{MATERIAL E MÉTODOS}

Neste estudo foram utilizados 30 pacus, com idade variando entre 5 meses a um ano, com peso médio de 588,1g (mínimo de $160 \mathrm{~g}$ e máximo de $1340 \mathrm{~g}$ ) e comprimento médio de $27,51 \mathrm{~cm}$ (mínimo de $19 \mathrm{~cm}$ e máximo de $37 \mathrm{~cm}$ ), oriundos da Piscicultura XV de Novembro, São João da Boa Vista, SP.

Os animais foram sacrificados com o uso de solução de Benzocaína® a 50ppm em solução aquosa de acordo com protocolo de Bioética número 849/2006 expedido pela Comissão de Bioética da Faculdade de Medicina Veterinária e Zootecnia da Universidade de São Paulo. Após a completa cessação dos movimentos operculares, foi feita uma incisão na região ventral para a coleta e registro fotográfico dos órgãos in situ.

O material coletado foi fixado em paraformoldeído 4\% em tampão fosfato e solução de Karnovsky, dependendo da técnica que foi realizada, microscopia de luz e eletrônica de transmissão.
Para a técnica de microscopia de luz, as amostras foram processadas segundo a técnica de Behmer et al. (1976), em séries crescentes de alcoóis, diafanização em xilol e inclusão em paraplast. Os fragmentos foram cortados com espessura de $4 \mu \mathrm{m}$ e corados com Hematoxilina-Eosina(HE).

O material destinado a microscopia eletrônica de transmissão foi emblocado com uso de resina Spurr (Spurr's kit - Electron Microscopy Sciences, USA). 0 material foi seccionado em ultramicrótomo da marca RMC modelo MT-RL efetuando-se cortes ultrafinos com espessura de 70-90nm, os mesmos foram colocados em grids de cobre de 200 mesh e em seguida contracorados com acetato de uranila a 3\% e citrato de chumbo. Os cortes foram observados em Microscópio Eletrônico de Transmissão da marca Philips Morgagni 268 D.

\section{RESULTADOS}

O rim de Piaractus mesopotamicus está localizado retroperitonealmente na região dorsal da cavidade celomática, dorsalmente à bexiga natatória e ventralmente à coluna vertebral, inserido entre as costelas (Fig.1A). Apresentou um formato de "H", sendo que a região média se expande lateralmente sobre a bexiga natatória. Esta região se apresentou como de união entre as porções cranial direita e esquerda do rim. Apresentou consistência gelatinosa e coloração vermelho viva (Fig.1B).

0 parênquima deste órgão constituia-se por numerosos glomérulos envoltos pela cápsula de Bowman, com suas duas camadas (visceral e parietal). Formadas por células pavimentosas com núcleo achatado constituía-se a camada parietal, e uma membrana muito fina formava a camada visceral (Fig.2A). Estas membranas limitavam a área das células que se encontravam no interior do glomérulo, que eram compostas por hemácias, linfócitos, trombócitos e células imaturas.

O estroma renal apresentou células hematopoiéticas e linfocíticas. Os túbulos contorcidos proximais eram constituídos por epitélio simples cúbico, com núcleo redondo basal. As células epiteliais apresentaram borda em escova e
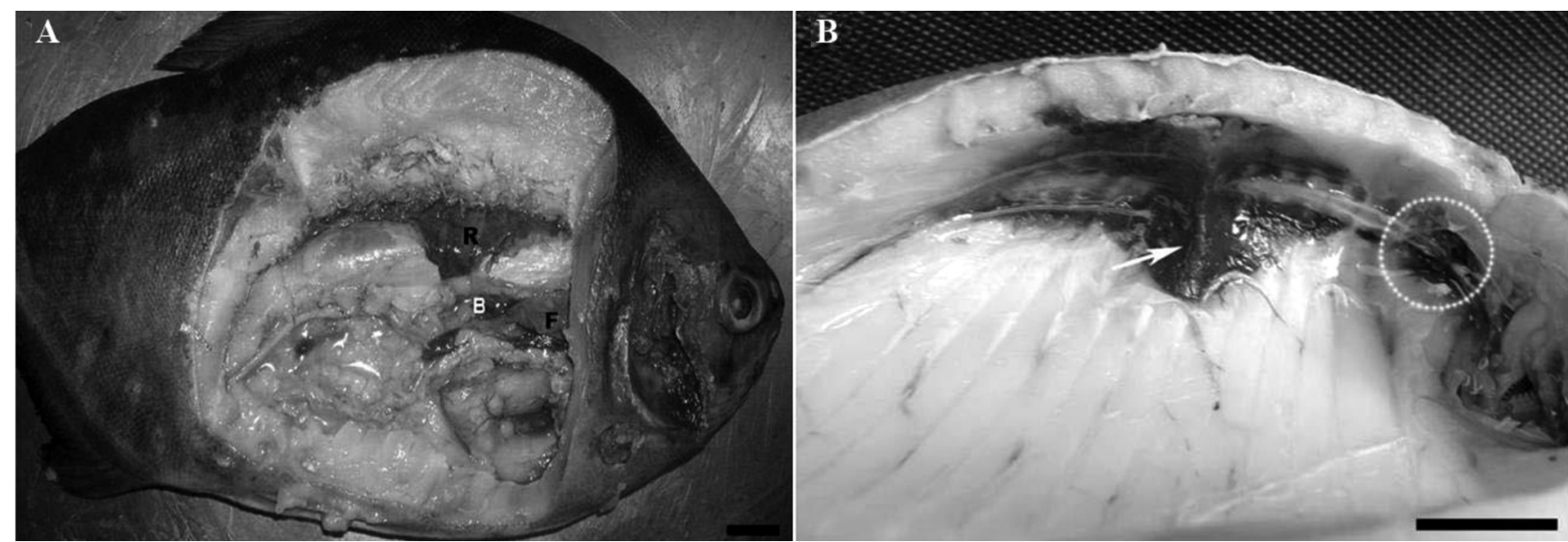

Fig.1. Vista lateral de um exemplar de Piaractus mesopotamicus. (A) Localização do rim (R), baço (B) e fígado (F) na cavidade celomática. Escala de barra: $1,0 \mathrm{~cm}$. (B) Vista lateral da região média do rim em forma de "H" (seta) e dilatação cranial ao rim demonstrando a presença do rim cefálico (círculo pontilhado). Barra: $1,5 \mathrm{~cm}$. 

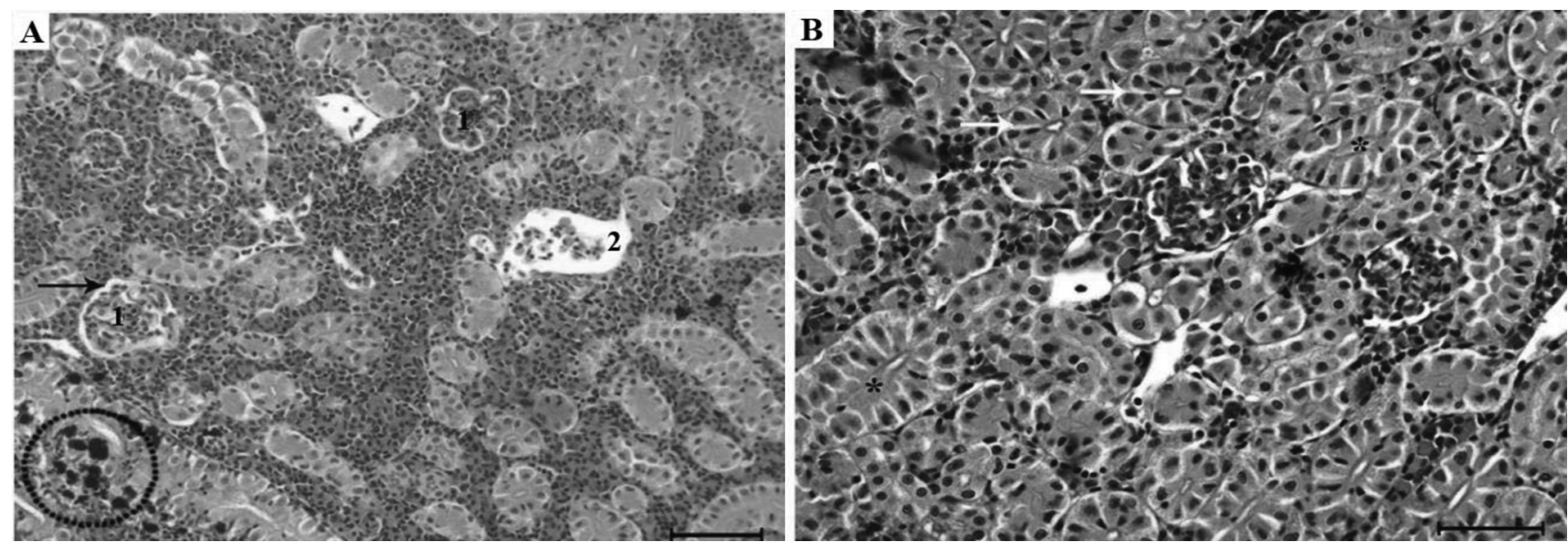

Fig.2. Parênquima renal de Piaractus mesopotamicus. (A) Glomérulos (1) e cápsula de Bowman (seta), além de vasos sanguíneos (2) e melanomacrófagos dispersos no citoplasma (círculo pontilhado). Barra: $50 \mu \mathrm{m}$. (B) Túbulos contorcidos proximais com epitélio simples (setas) e túbulos contorcidos distais com epitélio cúbico baixo apresentando luz central reduzida (*). HE, Barra: $40 \mu \mathrm{m}$.
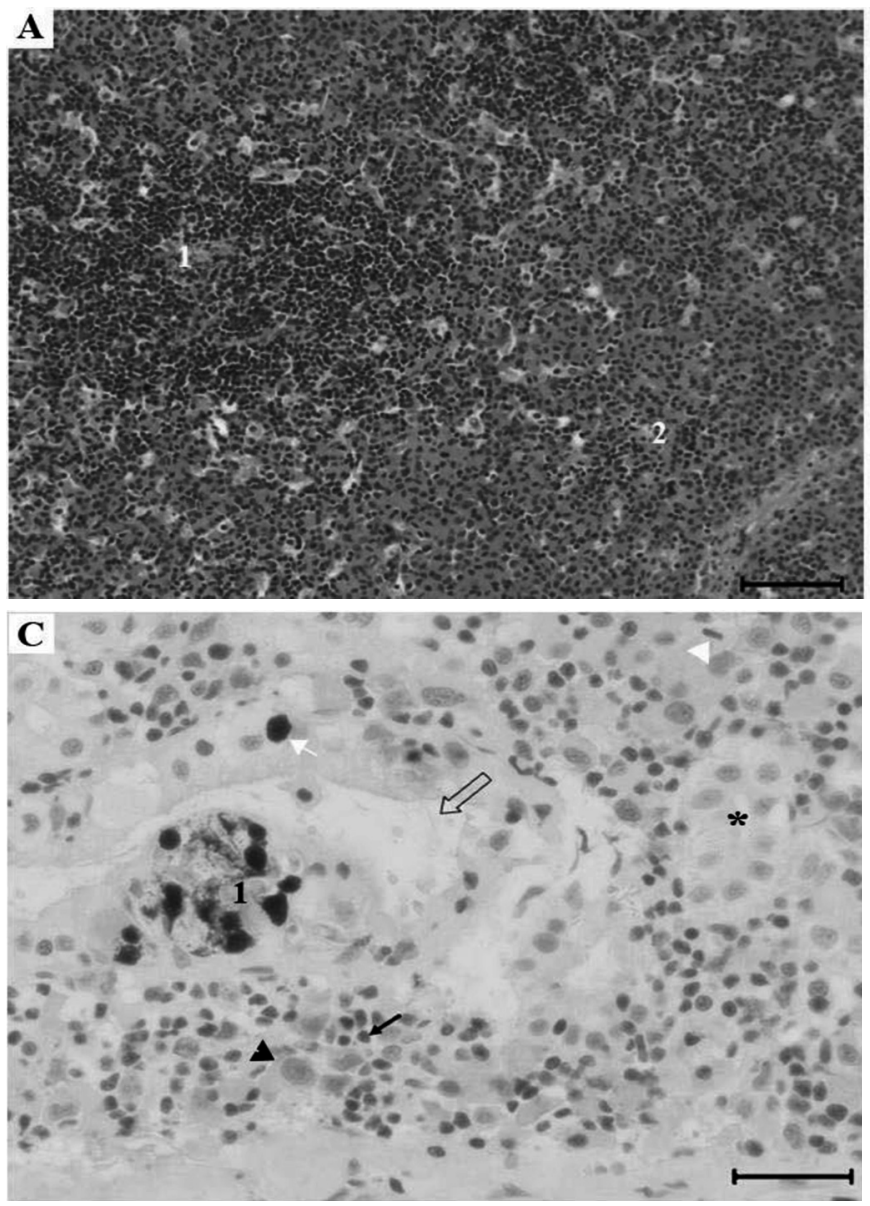

luz tubular central reduzida. Os túbulos contorcidos distais apresentaram epitélio cúbico baixo, com núcleos redondos basais e luz tubular central reduzida (Fig.2B). No tecido conjuntivo renal foram observados pequenos capilares, arteríolas e veias de grande calibre contendo hemácias e leucócitos.

O rim cefálico de Piaractus mesopotamicus está localizado na porção cranial do rim, caudalmente ao crânio e dorsalmente a porção cranial da bexiga natatória, lateralmente

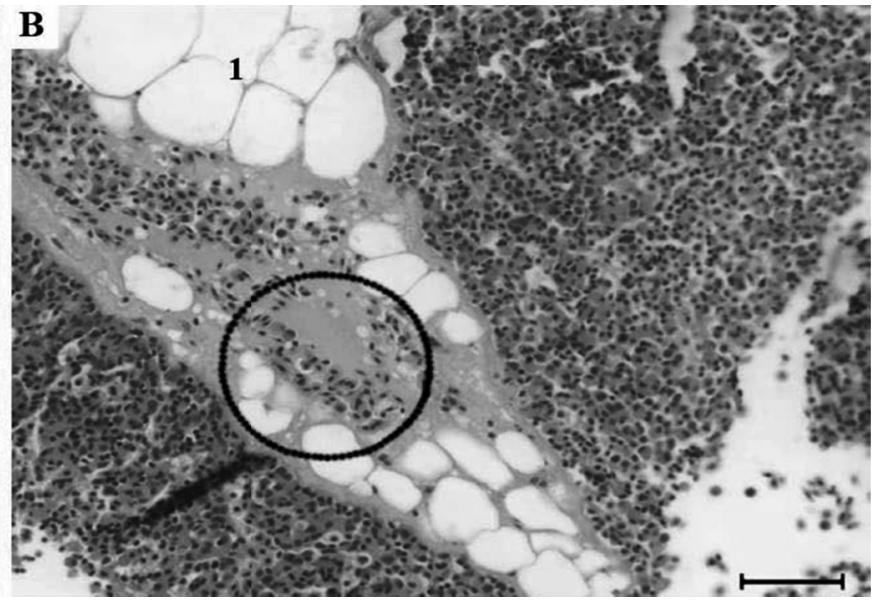

Fig.3. Rim cefálico de Piaractus mesopotamicus. (A) Região cortical (1) e medular (2). Barra: $50 \mu \mathrm{m}$. (B) Tecido adiposo unilocular (1) e vasos contendo hemácias (círculo pontilhado). Barra: $50 \mu \mathrm{m}$. (C) Vaso sanguíneo com hemáceas em seu interior (seta vazia); túbulos contorcidos proximais (asterisco), linfócitos (seta preta), célula reticular (cabeça de seta preta), trombócitos (cabeça de seta branca), melanomacrófagos livres (seta branca) e melanomacrófagos centrais (1). 0 parênquima é constituído em sua maioria por células sanguíneas relativamente frouxas. HE, Barra: $40 \mu \mathrm{m}$.

à região cervical da coluna vertebral. Apresentou uma porção direita e uma esquerda, consistência gelatinosa e coloração vermelho vivo (Fig.1B).

0 epitélio de revestimento constitui-se de uma camada de células pavimentosas com núcleo achatado, uma camada de tecido conjuntivo frouxo e uma camada de tecido adiposo unilocular.

A região cortical apresentou infiltrados mononucleares linfocíticos, eosinófilos, hemácias e basófilos. Células sanguíneas maduras e imaturas compõem um parênquima relativamente frouxo (Fig. 3A).

Vasos sanguíneos foram observados no tecido conjuntivo e, em algumas regiões, grandes vasos associados ou ao 
lado de uma arteríola (Fig. 3B). Melanomacrófagos livres, melanoacrófagos centrais, vasos sanguíneos, células reticulares, linfócitos e trombócitos apareceram dispersos pelo parênquima (Fig.3C).

Ultraestruturalmente no rim e rim cefálico foram observados eosinófilos, protrombócitos, mielócitos, linfócitos, neutrófilos, monócitos e macrófagos. Os eosinófilos apareceram como células grandes de formato arredondado com núcleo grande de margem irregular, apresentando cromatina heterogênea condensada próxima à membrana e um nucléolo pequeno excêntrico. Em seu citoplasma estavam presentes grânulos arredondados, vacúolos e mitocôndrias (Fig.4A e 5A). Foram observadas, presentes no parênquima o rim cefálico, hemácias, trombócitos, linfócitos e eosinófilos (Fig. 4B).

Protrombócitos se mostraram como células com núcleo grande em forma de ferradura com cromatina heterogênea condensada (Fig.5B). Os mielócitos apresentaram formato arredondado com núcleo grande e periférico, com cromatina condensada, citoplasma com muitos vacúolos, mitocôndrias, retículo endoplasmático rugoso e complexo de Golgi (Fig.5C).

Os linfócitos se apresentaram como células pequenas, com pouco citoplasma, algumas mitocôndrias, raros vacúolos e material granular disperso homogeneamente, núcleo grande e arredondado que ocupa quase toda a célula e apresenta cromatina condensada distribuída irregularmente (Fig.5D).

Células tronco apresentavam formato irregular com pequenas projeções citoplasmáticas e núcleo com reentrâncias (Fig.5E).

Os monócitos apresentaram formato irregular com pequenas projeções na membrana citoplasmática. Núcleo grande com uma reentrância bem visível e material granular condensado heterogeneamente na periferia. No citoplasma foi observado complexo de Golgi bem desenvolvido, grânulos, vesículas, mitocôndrias e vacúolos (Fig.5F).

Foram observados plasmócitos no parênquima apre- sentando formato arredondado a ovóide, núcleo grande e central com heterocromatina condensada na periferia. No citoplasma foram observadas mitocôndrias, vesículas, grânulos e material elétron-denso além de retículo endoplasmático rugoso (Fig.5G).

\section{DISCUSSÃO}

A localização do rim de Piaractus mesopotamicus na cavidade celomática foi a mesma encontrada em outras espécies de teleósteos (Fergunson 1995). A forma de " $H$ " apresentada pelo órgão demonstrou uma região central que se expande lateralmente sobre a bexiga natatória e dela partem a porção cranial direita e esquerda do rim e caudalmente a porção caudal direita e esquerda. Estas características anatômicas não foram relatadas em outras espécies. Hibiya (1982) relatou que a forma do rim dos peixes varia de acordo com a espécie e divide o rim dos teleósteos em duas porções: rim e rim cefálico, o mesmo foi descrito por Ellis \& Souza (1974) e Zapata $(1979,1981)$ Esta divisão também foi observada por nós em Piaractus mesopotamicus. Macroscopicamente não foi possível distinguir a separação entre o rim e o rim cefálico em animais jovens, fato já descrito por Becker et al. (2001), já em animais mais velhos o rim cefálico foi visto como uma dilatação do rim.

As análises microscópicas do rim desta espécie mostraram similaridades com o rim de outras espécies de teleósteos, apresentando em sua constituição glomérulos, túbulos contorcidos distais e proximais e vasos sanguíneos como fora descrito anteriormente por Ellis \& Souza (1974), Zapata $(1979,1981)$, Hibyia (1982) e Stoskopf (1992). Stoskopf (1992) relatou que o rim dos peixes não apresenta a alça de Henle, fato este confirmado em nossos estudos para a espécie em questão.

O rim cefálico foi localizado na extremidade da porção cranial do rim tal como descrito por vários autores em outras espécies de teleósteos (Ellis et al. 1976, Zapata 1980, Becker et al. 2001, Rocha et al. 2001). 0 rim cefálico é con-
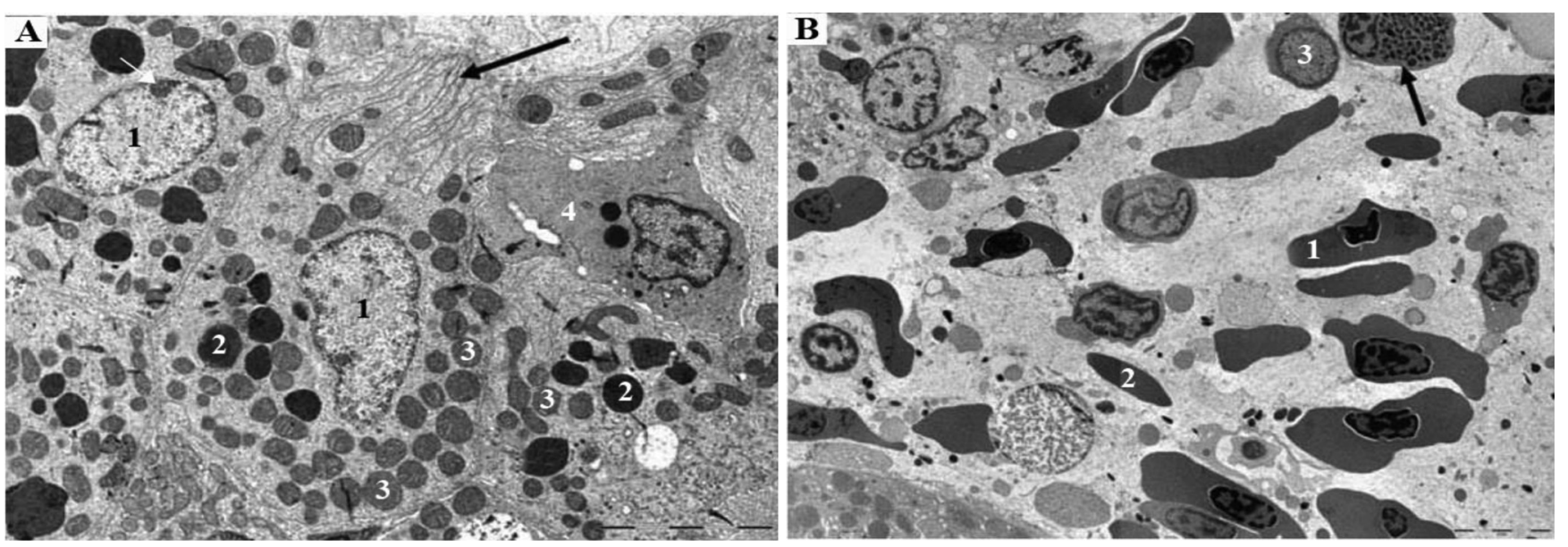

Fig.4. Eletromicrografias de rim e rim cefálico de Piaractus mesopotamicus. (A) Túbulo contorcido proximal em área de transição entre rim e rim cefálico; em células endoteliais foram visualizadas microvilosidades apicais (seta fina), núcleo irregular (1) com heterocromatina e eucromatina (seta branca), vacúolos elétron-densos (2), mitocôndrias (3) e entre as células vê-se uma célula limitante (4). Barra: $5 \mu \mathrm{m}$. (B) 0 parênquima do rim cefálico com presença de hemáceas (1), trombócitos (2), linfócitos (3) e eosinófilos (seta preta). Barra: $5 \mu \mathrm{m}$. 


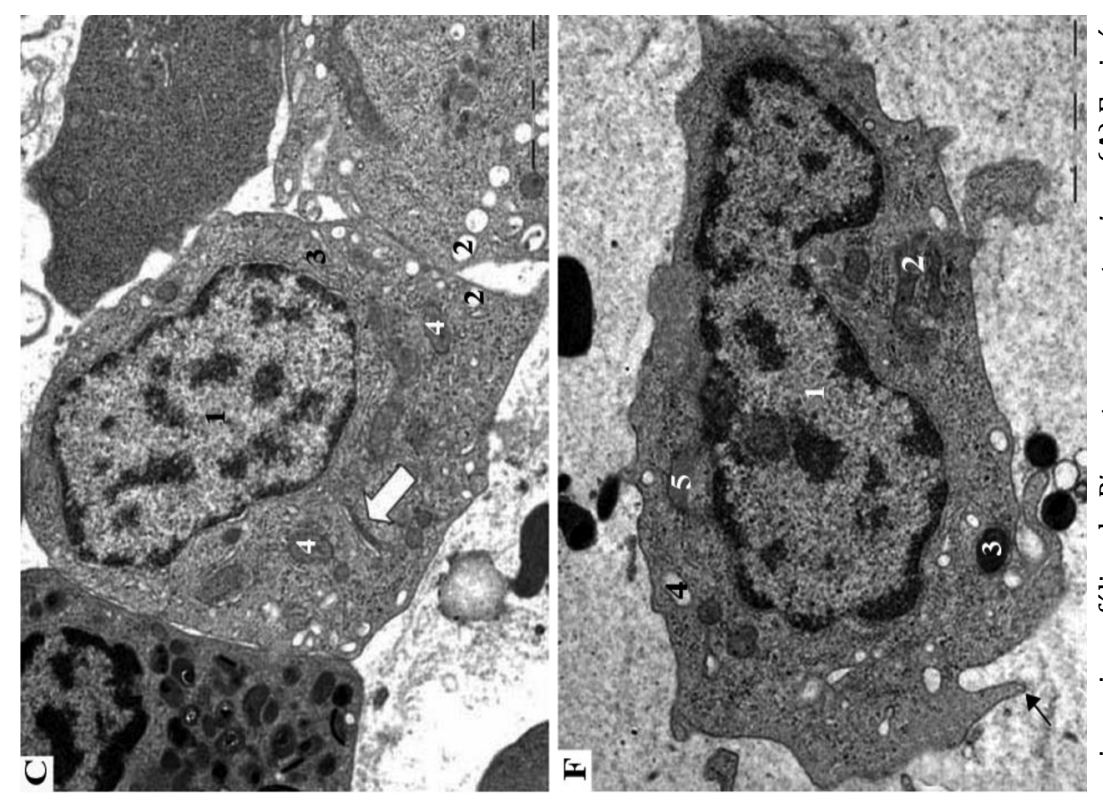

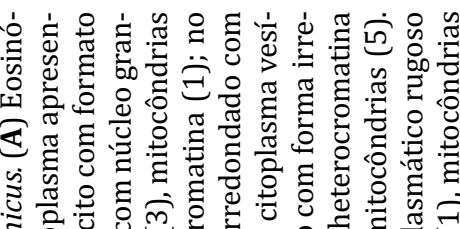

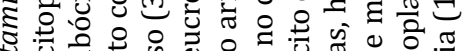
o 0 :

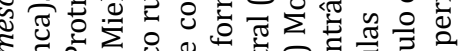

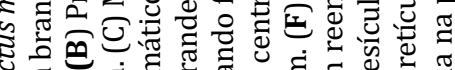
西

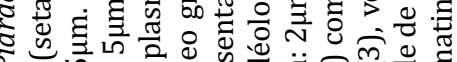

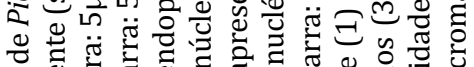

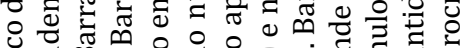

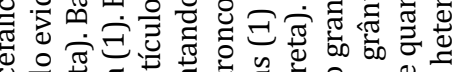

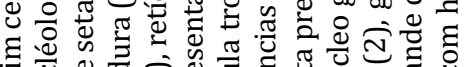

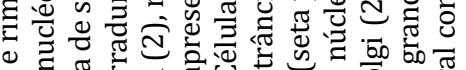

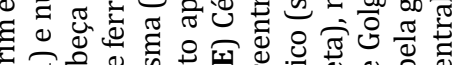

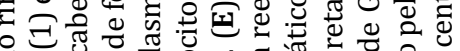

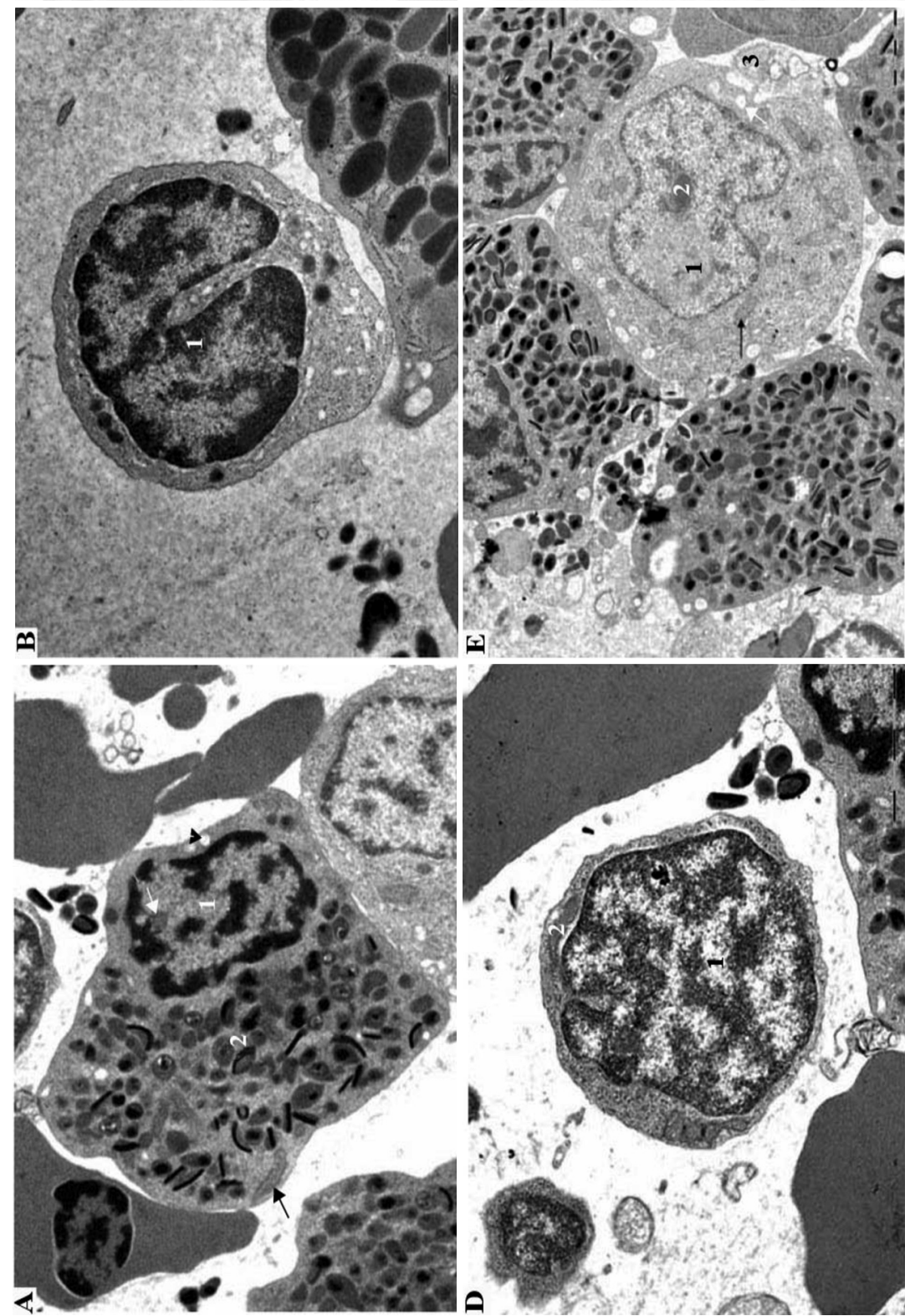

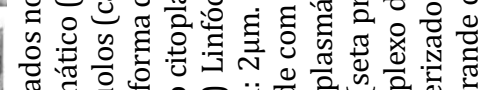

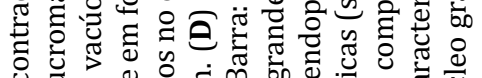

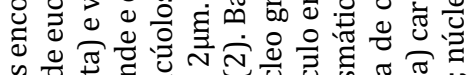

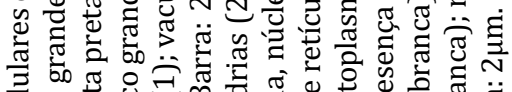

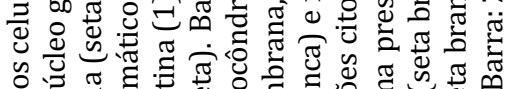

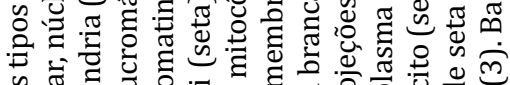

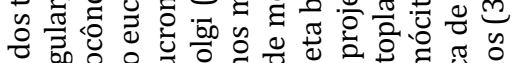

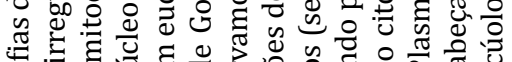

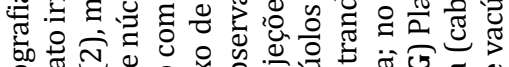

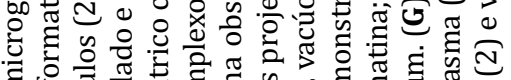
हू. 过 0 战

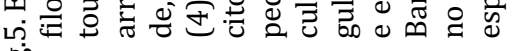
is

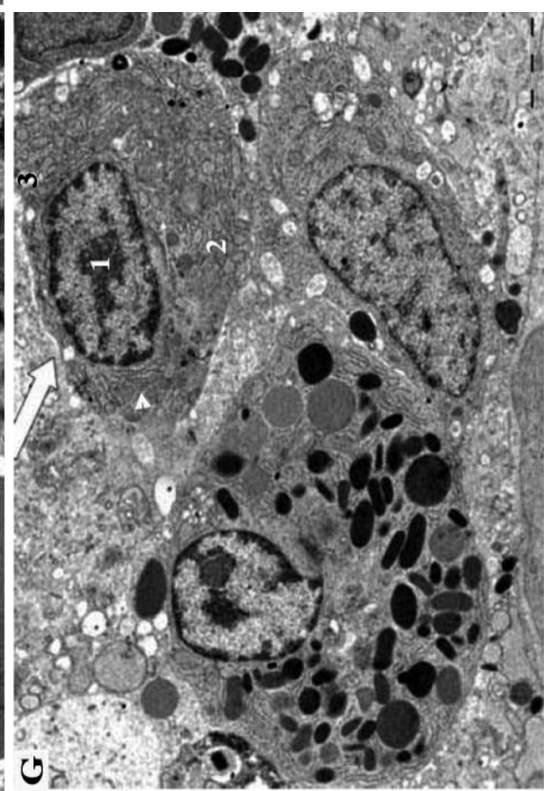


siderado o principal órgão formador de células do sangue de teleósteos (Bielek 1981) sendo composto por células hematopoiéticas em diferentes estágios de maturação ocupando o espaço extravascular (Esteban et al. 1989).

Este órgão mostrou-se como uma massa celular dividida em uma região medular e uma cortical e, na região de transição com o rim apresentou túbulos contorcidos proximais e distais, o que também foi relatado por Zuasti \& Ferrer (1988), Fergunson (1995) e Powell (2000) em peixes teleósteos. Este órgão continha diferentes tipos celulares como linfócitos, macrófagos, eosinófilos, melano-macrófagos células sanguíneas em diferentes estágios de maturação e vasos sanguíneos corroborando com o descrito em outras espécies de peixes por Chilmonczyk (1978), Miller et al. (1985), Zuast \& Ferrer (1988), Messeguer et al. (1991), Rocha et al. (1994, 2001), Mella et al. (2006).

\section{CONCLUSÃO}

Com base nos resultados encontrados podemos concluir que o rim e o rim cefálico de Piaractus mesopotamicus nos aspectos macroscópicos, microscópicos e ultraestrutural foram semelhantes a de outros teleósteos descritos anteriormente.

\section{REFERÊNCIAS}

Agius C. 1985. The melano-macrophage centers in fish: A review, p.85105. In: Manning M.J. \& Tatner M.F. (Eds), Fish Immunology. Academic Press, London.

Agius C. \& Roberts R.J. 2003. Melano-macrophage centers and their role in fish pathology. J. Fish Dis. 26 (9):499-509.

Becker K., Fishelson L. \& Amselgruber M. 2001. Cytological ontogenesis and involution of the thymus and head-kidney in juvenile and old domestic carp: Is ageing in fish a chronological or growth-related phenomenon? J. Appl. Ichthyol. 17:1-13.

Behmer O.A., Tolosa E.M.C. \& Freitas-Neto A.G. 1976. Manual de Técnicas Histológicas Normal e Patológica. Editora Edart, São Paulo. 456p.

Bielek E. 1981. Developmental stages and localization of peroxidatic activity in the leucocyts of the three teleost species (Ciprinus carpio L., Tince ince L., Salmo gairdneri Richardson). Cell Tissue Res. 220:163-180.

Chilmonczyk S. 1978. In vitro stimulation by mitogens of peripheral blood lymphocytes from rainbow trout (Salmo gairdneri). Annales d'Immunologie 129:3-12.

Ellis A.E. \& De Sousa M.A.B. 1974. Phylogeny of the lymphoid system. I. A study of the fate of circulating lymphocytes in place. Eur. J. Immunol. $4: 338-343$.
Ellis A.E. 1976. Leucocytes and related cells in the plaice, Pleuronectes platessa. J. Fish Biology 8:143-156.

Esteban M.A., Meseguer A., Garcia A. \& Agulleiro A. 1989. Erythropoiesis and thrombopoiesis in the lead-kidney of the sea bass (Dicentrarchus labrax L.): An ultrastructural study. Archs Histol. Cytol. 52(4):407-419.

Ferguson H.W. 1976. The relationship between ellipsoids and melano-macrophage centres in the spleen of turboy (Scophthalmus maximus). J. Comp. Pathol. 86:377-380.

Hibiya T. 1982. Digestive system - Liver, p.82-90. In: Ibid. (Ed.), An Atlas of Fish Histology: Normal and Pathological Features. Kodansha Ltd, Tokyo.

Mela M., Randi M.A.F., Ventura D.F., Carvalho C.E.V., Pelletier E. \& Oliveira Ribeiro C.A. 2006. Effects of dietary methylmercury on liver and kidney histology in the neotropical fish Hoplias malabaricus. Ecotoxicol. Environ. Safety 68:426-435.

Meseguer J., Esteban M.A. \& Agulleiro B. 1991. Stromal cells, macrophages and lymphoid cells in the head-kidney of sea bass (Dicentrarchus labrax L.): An ultrastructural study. Archs Histol. Cytol. 54 (3):299-309.

Messeguer J., Lopez-Ruiz A. \& Esteban M.A. 1994. Melano-macrophages of the seawater teleosts, sea bass (Dicentarchus labrax) and gilthead seabream (Sparus aurata): morphology, formation and possible function. Cell Tissue Res. 277(1):1-10.

Miller N.W., Sizemore R.C. \& Clem L.W. 1985. The phylogeny of lymphocyte heterogeneity: The cellular response for in vitro antibody responses of channel catfish leukocytes. J. Immunol. 133:2356-2359.

Powell D.B. 2000. Blood and lymphatic vessels, p.441-448. In: Ostrander G.K. (Ed.), The Laboratory Fish. Academic Press, San Diego.

Rocha E., Monteiro R.A.F. \& Pereira C. 1994. The liver of the trout, Salmo trutta fario: A light and electron microscope study. J. Anat. 185:241-249.

Rocha R.M., Leme-Dos Santos H.S., Vicentini C.A. \& Da Cruz C. 2001. Structural and ultrastructural characteristics of interrenal gland and chromaffin cell of matrinxã, Brycon cephalus Gunther, 1869 (Teleostei-Characidae). Anat. Histol. Embryol. 30:351-355.

Severi W., Rantin F.T. \& Fernandes M.N. 2000. Structural and morphological features of Piaractus mesopotamicus (Holmberg, 1887) gills. Revta Bras. Biologia 60(3):493-501.

Stoskopf M.K. 1992. Fish Medicine. W.B. Saunders Company, Philadelphia. 882p.

Tavares-Dias M. \& Moraes F.R. 2004. Hematologia de Peixes Teleósteos. M. Tavares-Dias, Ribeirão Preto. 144p.

Zapata A. 1979. Ultrastructural study of the teleost fish kidney. Develop. Comp. Immunol. 3:55-65.

Zapata A. 1980. Ultrastructure of elasmobranch lymphoid tissue. I. Thymus and spleen Develop. Comp. Immunol. 4:459-472.

Zapata A.G. 1981. Lymphoid organs of teleost fish. II. Ultrastructure of renal lymphoid tissue of Rutilius rutilius and Gobio gobio. Develop. Comp. Immunol. 5:43-52.

Zuasti A. \& Ferrer C. 1988. Granulopoiesis in the head kidney of Sparus auratus. Archs Histol. Cytol. 51(5):425-431. 